\title{
An Arranged Marriage: Police - Media Conflict \& Collaboration
}

\author{
Robert Chrismas \\ University of Manitoba, Mauro Centre for Peace and Justice
}

\begin{abstract}
Media and police professionals are bound together in interdependent, and often tense, working relationships. For different purposes both professions need to work effectively together while simultaneously retaining independence from each other. These complex inter-reliant relationships create unique challenges that often call for improvement. This essay examines whether relationships between interdependent professional organizations can be improved through a collaborative problem-solving intervention, based on the interactive methods of facilitated dialogue and appreciative inquiry. The article describes a case study of a large Canadian police agency working with local media outlets to improve their working relationship. It highlights the importance of conflict analysis followed by effective change management strategies in implementation of collaborative solutions that meet everyone's needs. This case study illustrates dynamics that generalize to organizations that have strong organizational cultures and are highly independent and simultaneously required to work together. Some examples of such organizations are military, prison guards, scholars, medical professionals, social workers, teachers, lawyers and most government agencies.
\end{abstract}

Keywords: Facilitated dialogue; Collaboration; Organizational culture; Change management

Les médias et les corps policiers sont à la fois interreliés et interdépendants, et leur collaboration est souvent tendue. Dans divers objectifs, ils doivent travailler efficacement ensemble tout en maintenant leur propre autonomie. Ces relations complexes donnent lieu à des difficultés auxquelles il faut remédier. Cet essai porte sur les améliorations pouvant être apportées dans les relations entre deux organisations professionnelles interdépendants par l'entremise d'une intervention visant à résoudre les problèmes fondée sur des méthodes interactives de facilitation du dialogue et d'interrogation appréciative. Cet article décrit un cas où une grande agence policière canadienne a collaboré avec des médias locaux en vue d'améliorer leur relation de travail. On y souligne l'importance de l'analyse des conflits suivie de stratégies efficaces de gestion du changement dans la mise en cuvre de solutions axées sur la collaboration et répondant aux besoins de tous. Cette étude présente les dynamiques communes aux organismes indépendants dont la culture d'entreprise est bien affirmée, et devant travailler en partenariat. Parmi ces organisations, on compte l'armée, les gardes de prison, le secteur universitaire, le corps médical, les travailleurs sociaux, les enseignants, les avocats et la plupart des organismes gouvernementaux.

Mots-clés : facilitation du dialogue; collaboration; culture d'entreprise; gestion du changement

\section{Introduction}

Recent decades have seen ever-increasing public access to information, resulting in higher accountability in the policing profession. Law enforcement agencies have felt greater need for effective messaging to demonstrate transparency and to satisfy the public appetite for immediate, accurate information about crime, justice and community issues. Reporters and news outlets are under constant pressure to produce stories in a demanding and competitive environment. Internet based news casts often require hourly updates on top of traditionally demanding publishing deadlines, all intensifying pressures on reporters. As a result, the interdependent police-media relationship is often strained. 
This paper examines how police-media tensions may be reduced for more effective working relationships. It is not presented as a report on a comprehensive research project. Rather, it offers insights into the dynamics of interdependent working relationships, and highlights opportunities for properly designed and controlled future studies. As an active police officer, I offer a practitioner's perspective. I am a senior ranking officer in a Canadian police agency with 1,500 officers, and have given interviews and worked with numerous reporters in print, radio and film media on policing related issues. I have also taught aspects of media relations to police officers in training to be public information officers for their policing agencies. In order to protect their identities, the police organization examined for this case study is referred to as "A Police Agency" (APS), and individuals will be referred to generically as police officers or reporters. The term "media" will refer to the broad spectrum of news outlets including television, radio and print formats.

A literature review provides context and highlights elements of police-media roles and relationships. It describes theories that support analysis of this conflicted relationship, as well as ways to reconcile and move forward. A facilitated dialogue exercise conducted between APS and local media outlets is described as a case study to highlight dynamics that generalize to other scenarios wherein independent agencies must work together. The findings highlight the complexity of working relationships, and that conflict resolution is more an ongoing continuous process than a singular event. This exercise underlines the importance of conflict analysis, effective resolution processes, and attention to how solutions are carried out. Failure to attend to any of these three key areas likely results in failure to improve collaboration and mutual needs attainment.

\section{Police-Media Relations}

Some authors have described the relationship between policing and the media as symbiotic (Boyle, 1999; Guffy, 1992), in that both professions are highly independent, mutually supportive and also competitive. Police need media for outreach to the public while they are simultaneously cautious of the intense scrutiny that the media is often perceived to fuel. Media are challenged to balance public accountability, reporting on alleged police infractions, while maintaining working relationships with the very officers they need to illicit information from. Cooke and Sturges (2008) characterized police-media relationships as complex loops of interdependence. Police need media for critical information releases and also must keep certain details secret. Reporters are bound to work with the police in order to gather information that is critical for substantial portions of the daily news (Becker, 1967). During major events, reporters and police officers must work together to release important information to the public (Bellew, Caeti, \& Liederbach, 2004).

Police need media for public appeals and as the main channel for public legitimization and transparency. At the same time, they must maintain a level of secrecy, to preserve the integrity of ongoing investigations and to protect the dignity and privacy of victims and the public that they serve (Guffy, 1992). They must withhold information from the media, while simultaneously asking for their assistance. Reporters seek to establish trusting relationships with police sources while simultaneously remaining at arms length, in order to preserve journalistic objectivity and independence on issues such as alleged police corruption or misconduct. In some cases, reporting on alleged police misconduct creates tension in the relationships that reporters are simultaneously striving to develop (Surrette, 1989).

Selki and Bartoszek (1984) found that both police officers and reporters are indoctrinated early in their careers through formal training, mentoring, and experience, with cynicism and distrust over their respective intentions and roles. Having worked in law enforcement for over 28 years, I can attest that Selki and Bartoszek's findings remain apposite today. In this age of instant access to information through the Internet, in which police officers are routinely recorded and confronted regarding actions they have taken in their work, they are arguably even more cautious of the media.

News stories about work related issues often personally impact police officers' personal relationships with friends and family, and can adversely impact their careers. Reporters, on the other hand, can feel frustration over being stonewalled by the police regarding details of high public-interest 
cases. Issues that are of highest interest to the media and the public are often the most sensitive to police, and require the highest secrecy and control of information that can be released.

It is also important to note that neither media nor police are homogeneous groups. Internal conflict occurs as reporters are in competition with each other, continually seeking inside information in order to beat their competitors with leading stories (confidential sources). This competition creates tension within law enforcement agencies as many reporters continually seek confidential police sources to circumvent formal information channels. This dynamic also creates tension for police officers who are often encouraged to be open and forthcoming with the media while, at the same time, they are closely regulated over information that can be released. Senior police officials have diverse opinions about how police officers should interact with media. Some support open transparency between all police officers and media, while others feel only public affairs personnel or senior officers, and not others, should be the conduits of information to the press. Both approaches have merit, however they both must include controls, as inappropriate or untimely release of information can undermine ongoing investigations, breach privacy laws, or place officers and the public in danger.

All of these contradictory needs and mandates inevitably create tension within and between media outlets and police agencies. The dynamics make police-media relationships challenging, yet they are bound to work together. For these reasons Sir Robert Mark, Commissioner of the British Metropolitan Police from 1972 to 1977, characterized the police-media relationship as "an enduring if not ecstatically happy marriage" (Cooke and Sturges, 2008).

\section{A Case Study: APS and Media}

APS's relationship with local media outlets can generally be characterized as consistent with Sir Robert Mark's description (Cooke and Sturges, 2008); it resembles an arranged marriage with a long history of occasional domestic disputes. For the most part, however, the relationship has been productive, particularly in recent years wherein the APS Chief and executive have made transparency and public accountability a priority. Consistent with worldwide policing trends the APS has a dedicated Public Information Office (PIO), which coordinates the outflow of information to the media on significant or newsworthy events (Boyle, 1999). While information is released through other means, such as monthly crime statistics on the APS website and annual reports, significant events occur daily, requiring APS members to answer reporters' questions. Ongoing experience has taught police agencies that being proactive and putting appropriate information out early can prevent inaccurate or negative stories from developing. Executive members in APS's Chief's office approve messages and the PIO conducts daily briefings on significant events. The PIO maintains relationships with key members of the journalistic community, ensuring the APS is enabled with mechanisms for controlled public messaging and some ability for damage control when it is required. On occasion, reporters have discovered sensitive information that could compromise ongoing investigations and operations, in some cases endangering the safety of police officers and citizens if it was released too early to the public. For instance, on occasion reporters learn of search warrants that are being prepared. If news of a search warrant is released, suspects can destroy evidence, flee, or even lay in wait to attack police officers when they execute the warrant. PIOs, or any officer for that matter, with good working relationships with reporters can negotiate the necessary delay in reporting, in exchange for favors such as an exclusive story at a later time. As a major case coordinator I have had first-hand experience and can say this ability to negotiate is critical.

From 7:00 AM to 5:00 PM, seven days a week, APS PIO staff are available for media inquiries, and they conduct a briefing on major events at 11:00 AM most days. On days when a briefing is not held, media releases on major events are sent out by mass e-mail. Major events that involve the police, and are of interest to the media, however, happen 24 hours a day. To fill the void after-hours, the duty office acts as the official spokesperson for the Police Service. A senior ranking officer, overseeing frontline operations of APS, staffs the duty office at all times, around the clock. Benchmarking with two other police agencies that are similar in size to APS, it was learned that all agencies have different communication strategies. One agency has a PIO office that runs Monday to Friday 8:30 AM to 4:30 PM, 
and they have no coverage on weekends. Another agency has a senior officer that works as a street supervisor 24/7, and that officer addresses the media as required when the PIO is closed. All agencies examined have different relationships with the media, therefore the question about reporting mechanisms may be less relevant than having a process for improving working relationships, which this paper seeks to reveal.

The APS duty officer is the designated official spokesperson to the media when the PIO is off duty. The duty officer often becomes so busy dealing with real-time operational command issues, that he or she may find calls from the media distracting and disruptive. Consequently, reporters have been restricted to calling a dedicated phone line in the duty office between 5:00 AM to 7:00 AM, and 10:00 PM to midnight, and at no other time. If the duty officer is not busy with urgent business, they will answer the dedicated media line during the specified hours. Outside of those hours duty officers do not answer that line.

As a duty officer myself, I routinely interacted with other duty officers and reporters. Concerns were being expressed on both sides about the effectiveness of the working relationship. Duty officers reported it was annoying when reporters called every day, asking vague questions such as "anything to report?" Some duty officers view asking non-specific questions, known as "fishing," as laziness by reporters. Officers have often stated that reporters should do their own preliminary work on stories and then call with specific questions, as it is not the role of the police to create stories for media. Duty officers were finding that reporters often appear to not understand the duty officer's role, asking officers for information that is impossible or inappropriate for them to release. For example, asking about events that happened the previous day is considered inappropriate because detectives are already assigned and the duty officer rarely has sufficient up-to-date knowledge to comment appropriately.

Reporters expressed frustration at inconsistent levels of cooperation from different duty officers. For instance, some provided sound bites while others would not. Some officers were more willing than others to make inquiries, look up police reports, or even call officers at the scene of a major event for updates that would assist reporters in preparing their stories. Reporters also claimed that the duty office hours of availability made it difficult for them to meet broadcast and print deadlines. Reporters have complained that there is obvious inconsistency between the individual duty officers and will even alter their approaches depending on who is working in the duty office on particular shifts. Some reporters have attempted to circumvent police public information processes. For instance in some cases reporters' associates from other provinces have called the duty office outside of agreed upon hours, or called the inquiry line asking to be transferred to the duty officer, and then denying knowledge about the time periods in which they were supposed to call. On some occasions reporters have recorded conversations as a sound bite, without the duty officer's consent. These small infractions tend to damage relationships between all of the stakeholders and propagate a milieu of distrust.

The conflict described above is rooted partially in the way that the APS PIO function is structured. Answering media inquiries is an add-on responsibility for duty officers who operate in realtime and often demanding command roles. Personalities are a significant factor as different duty officers have varying levels of comfort, experience, and training in conducting media interviews. Some are more receptive to speaking with the media than others. Some have had bad personal experiences as a result of news reports. Reporters all have different levels of experience and different needs as well. Experienced reporters tend to have a better understanding of the importance of establishing relationships with people who they intend to later ask for information. These dynamics are somewhat unique as they relate to police-media relations; however, there are also aspects and dynamics that can be understood through existing research and literature on general conflict analysis and resolution. The following review highlights some applicable theories and existing literature.

\section{Literature Review}

Druckman's situational model locates the source of every conflict on a spectrum between individual characteristics of the participants and social systems (Cheldelin, Druckman, \& Fast, 2003). The model 
suites analysis of police-media tensions as both groups are comprised of professionals with strong individual characteristics. Both professions have powerful ethos that tend to propagate strongly defined organizational cultures.

Zwell (2000) described organizational culture as comprising language, beliefs, shared knowledge and characteristics that bind groups so they can work well together. Both policing and journalism are clearly defined professional cultures, steeped in values, norms, and a strong sense of group affiliation by their members. Both professions also have shared goals and values that may serve as a starting point for reconciliation. While the media are profit-oriented commercial businesses, for the most part, they provide services that resemble the police mandate to act in the public interest. Therefore, goals serving the public good are a shared value upon which conflict solutions could be based. Understanding their respective cultures facilitates analyzing police-media conflict and identifying potential resolution strategies.

Police agencies have unique organizational cultures (Crank, 1998; Niederhoffer, 1967; Paoline, 2000; Prenzler, 1997; Skolnick, 1994; Van Maanen, 1974, 1978; Westley, 1970). Nickels and Verma (2008) noted themes that mold police culture commonly include: danger and ambiguity, authority to use force, discretion, estrangement from civilians, bureaucracy, shift-work, routine contact with criminals, antagonism between front-line officers and managers, and occasionally vague and conflicting mandates.

Journalism has equally distinct language and core values (Deuze, 2005). Research has confirmed that objectivity and impartiality are values that permeate journalism throughout the world (Hanitzsch, 2005; Herscovitz, 2004; Ramaprasad, 2001; Weaver et al., 2007; Weaver, 1998). Splichal and Sparks (1994) surveyed first-year journalism students in 22 countries and found consistent similarity in their stated desire for independence and autonomy.

Elements in police and journalism cultures can create barriers to communication, as members of both groups inevitably tend to view the world as us vs. others. But the two professions are not to be confused as being the same; as pointed out several times throughout this paper, they are quite different. The police generally report to inform on issues that impact public safety, and to provide the public a sense of closure on major issues, generally keeping their opinions about political aspects to a minimum.

Media report on a much broader spectrum of issues and delve into them in more depth. Reporters can challenge political aspects of issues that the police, as politically neutral public servants, strive to avoid (Scheufele, 1999). News reports can drive political agendas by focusing on specific issues and framing stories in certain ways (McCombs, 1972). Reporters seeking information or confirming facts for stories that the police have no interest in, or which show the police in a poor light, can cause domestic tensions to rise. When the focus is on public safety, however, we find common ground that serves police interests and makes news stories of high public interest. The distinguishing cultural elements of policing and journalism can be useful for predicting behaviour, identifying where tensions may develop or already exist, finding common goals, and solving conflicts.

While policing and journalism are defined professions, they are comprised of individuals, each with their own personal characteristics. Police and news agencies are made up of individuals from diverse backgrounds, experiences, educations and attitudes. Cheldelin, Druckman and Fast (2003) have underlined how distinct professions are also internally divided. Individual police officers and reporters identify with their respective professions while they are frequently polarized and conflicted within their organizations. I have known reporters who disagree with their editors on the focus of stories published, and who disagree with the approaches other reporters take on stories. Similarly in policing, many if not most police officers disagree with at least some laws or policies they are required to enforce, and disagree with the attitudes and methods of some colleagues. Police officers come from all walks of life. They learn to work within a common framework and value system in order to function within their agencies. However, officers also have their own individual idiosyncrasies and beliefs that are shaped by unique backgrounds, experiences and education.

Sandole (2009) accurately describes the dynamics of police-media relations through the range of conflict resolution types (cited in Cheldelin, Druckman, \& Fast, 2003, p. 49). Sandole described approach-approach scenarios, in which both parties want to resolve issues, as the optimum opportunity for collaboration. In approach-avoidance scenarios one side wants change, while the other wants to avoid the 
conflict (cited in Cheldelin, Druckman, \& Fast, 2003, p. 49). The police-media relationship appears to be an approach-avoidance scenario as reporters generally wanted change and the police generally were seeking to avoid the issue. This is explored more in-depth later in the paper.

Simmel (1955) summarized five potential general patterns of conflict resolution: (1) disappearance of the object of the conflict, (2) victory for one party, (3) compromise, (4) conciliation, and (5) irreconcilability (cited in Schellenberg, 1996, p. 66). While dated, Simmel's theory has withstood the test of time and appears highly relevant here. Within the framework of Simmel's model, this case study describes the transformation of police-media conflict by reducing structural barriers, and achieving shared solutions through conciliation. The goal was not victory for one party over the other, or compromise, but, rather, the creation of win-win solutions through collaboration.

Analysis of this conflict also begs the question; how should potential solutions be implemented? Scholars have found that the biggest reason for the failure of organizational change is that not enough thought has been applied to their impacts on people (Bridges, 2003).

Administrators must recognize external factors that they have little or no control over, and the psychological effect that change can have on people (Cameron, \& Green, 2004). Lewin (1947) was a pioneer in managing organizational change, focusing on the human aspects that can cause initiatives to fail. He suggested that leaders must prepare people psychologically to understand the need for change (the "unfreezing" stage). In the anchoring stage ("refreezing"), the changes that have been made are internalized and accepted (Lewin, 1947). Awareness of these human resource dynamics and effective change management skills can enhance the success of changes that flow from effective conciliation.

Yet another aspect to consider is who runs the process of change. Sampson (2003) studied peace building in conflicted societies, describing the risk of community members being seen as traitors to the local group when they return from peace building summits. In this scenario, police officers and media managers attending meetings could be seen as not representing all members of their respective groups. As described earlier, both the police and media have strong organizational cultures, but neither are homogenous groups.

This paper explores whether improved collaboration and communication between two interdependent organizations, with intergroup tensions, results from a conciliation strategy, based on effective analysis of the structural/situational issues, collaborative problem solving, and effective change management. The objective is to improve police-media relationships for increased effectiveness in both groups. The broader goal is to understand dynamics of collaboration that generalize to diverse agencies that must work together interdependently.

\section{The Collaboration}

A meeting was arranged between media managers and APS duty officers to seek collaborative solutions to problems that were identified in conversations with members of both groups. My observations are based on informal discussions with fellow duty officers, past and present, and reporters from print, radio, and televised news agencies that deal with the APS duty office after hours. Full-time PIO officers, past and present, were also interviewed in this brief, informal assessment of people's attitudes, impressions, and opinions, as well as their perceptions of structural challenges that were exacerbating police-media tensions. These discussions happened in the normal course of my work as a duty officer, and I later recognized the situation as an opportunity for improved working relationships between the police and media. No university ethics approval was sought as this exercise was conducted entirely within the context of a business meeting between the police and the media, and all involved were fully aware that any results would be recorded, reported and acted upon.

PIO staff members were included because they deal face-to-face with the media on a daily basis and they are an integral part of the existing APS public relations structure. The existing conflicts appeared to involve attitude, experience and structural constraints mirroring the competing needs of the police and media agencies. Dr. Sean Byrne of the University of Manitoba Arthur V. Mauro Centre for Peace and Justice was consulted on how to best run a solution-seeking meeting between these two groups (2010). He 
suggested separating the stakeholders into mixed groups and challenging them to identify problems that could be addressed. He further suggested that the groups could then be challenged to identify potential solutions that could then be discussed and prioritized by the entire group. In this way, police and media stakeholders could develop shared solutions, and both would feel ownership in the resulting changes (Byrne, 2010).

In this day and age, it is extremely difficult to get busy professionals into a meeting for a full day. Therefore, I arranged a half-day meeting with as many duty officers and media representatives as possible. The PIO office provided a list of senior managers from local media outlets that could best speak to how their news staff interacts with the APS duty office. The initial invitation that was sent out emphasized collaboration and shared solutions, setting the tone for the planned meeting. All three APS PIO staff members attended, along with six media representatives and five police commanders who work fulltime in the duty office. Unfortunately, the other four duty officers could not attend. Six senior journalist-managers represented the media from print, radio, and televised news agencies. Exercises were designed to create consensus, identifying problems and then developing collaborative solutions. The anticipated outcome was that consensuses would emerge on some shared solutions. The optimistic longterm goal was to reach a 'tipping point' at which the police and media would become less adversarial and become more team oriented, despite their differing mandates (Gladwell, 2002).

The challenges perceived by the participants needed to be reframed from an adversarial to a collaborative approach, moving parties from an approach-avoidance to an approach-approach dynamic (Sandole, 2009). Moving parties in both groups to collaborate would be more conducive to removing structural barriers to working together (Simmel, 1955). Most of the media and police stakeholders perceived structural barriers around the times that media are allowed to call the duty office. The participating media stakeholders all expressed willingness to work together for improved processes; the police were more mixed in their receptiveness to the idea. Hence, my assessment of this relationship was an approach-avoidance scenario within Sandole's model (2009). The media were generally seeking change and the duty officers were somewhat willing to collaborate, although some were not interested in working with the media. Therefore, I predicted varying degrees of success with participating duty officers, and greater success among the media representatives. About half of the duty officers expressed willingness to change and cooperate, but were still structurally challenged (frustrated at answering media phone calls). Most of the media representatives spoken to perceived structural barriers in the way they received information from the duty office, and they all expressed willingness to cooperate in creating changes. Several reporters expressed structural challenges within their own systems, such as the requirement to seek three confirmations of facts before a story could be released, a barrier that falls outside of the scope of this conflict analysis.

Some of the invited reporters declined to participate in my proposed meeting. Some may have declined as a result of a negative attitude regarding collaboration, or to avoid the perception that they were being co-opted by the police. No data came to my attention to indicate that this occurred. However, in the interest of a completely fair and objective analysis, this possibility could be examined in future research. The reporters that attended the meeting were very receptive and appreciative at being asked to participate in a process to improve communication and cooperation.

No deception was involved, and the goal to improve the working relationship between the two groups was clearly stated. Ground rules were provided verbally and in writing to ensure that the meeting was respectful and productive. The ground-rules about respectful behaviour were referred to several times throughout the meeting, and a debriefing occurred at the end of the meeting. Although I am a member of the APS, this problem-solving meeting was modeled after traditional mediation processes and I was careful to ensure that all parties were given an equal hearing. The workshop was meant to be a transformative process in which participants gained a better understanding of each other's roles. I also strived to make it a positive experience, consistent with appreciative inquiry processes that are described by Sampson et al. in their book, Positive Approaches to Peacebuilding: A Resources for Innovators (2003). A particularly useful aspect of the appreciative inquiry model, in this case, was asking the participants to recall things that have worked well in the past. This is why I invited senior supervising 
journalist managers; they have been around long enough to know what has worked in the past. The second reason was the need for people who have the authority to change policy, as well as the credibility to take back positive outcomes of the meeting and train and encourage their colleagues.

Refreshments and food were provided by the APS, and the room (in a city office) was set up in a circle to facilitate an open discussion and sharing of ideas. After introductions, I distributed an agenda and ground rules for the meeting, asking for everyone's agreement to maintain a respectful work environment. I explained the agenda and advised that there would be no surprises. I also advised that the syndicate groups would be mixed with members of the police and the media in order to encourage collaboration. I conducted a brief presentation on the history of police-media relations and how they have evolved, in particular with advancing technology and its related challenges. For example, I described how it is not uncommon for the media to hear police calls on their radio scanners and arrive at crime scenes before the responding police. This presents unique challenges for duty officers when reporters ask them for updates. I led a discussion and outlined the differences between zero-sum games in which there is a loser and a winner, and win-win solutions in which everyone gains (Jeong, 1995). I explained that the goal was to avoid linear win-lose thinking and instead seek win-win solutions (Jeong, 1995). I conducted this discussion in an interactive format in order to engage participants for maximum buy-in.

The larger group was divided into three breakout groups, so that one of the three PIO office staff could be in each group. Media and police members were distributed randomly and equally between three groups, and clear instructions were provided along with copies of the detailed exercise plan. Three separate breakout rooms were used, and easels and markers were provided. I moved from room to room and encouraged the groups to identify problems and appoint spokespersons to present each group's findings. After 30 minutes, the three groups were joined back into a larger group and the findings were presented. A larger discussion was held to rank the identified problems according to priority. The three groups were consistent in the major issues that were identified, and reaching consensus on the main issues was straightforward. The same process was followed for the solution finding phase, and the follow-up discussion was oriented around agreement on the best attainable solutions going forward.

Police participants spent considerable time describing, for the media, the role of the duty office, and the frustration that is caused when reporters call for information that cannot be provided. The media representatives did not realize that duty officers are working in real-time command of major incidents, ensuring sufficient resources, making notifications internally and to other agencies, and directing investigations. Once a case is assigned to detectives it is inappropriate for the duty officer to attempt answering questions for several reasons: they do not have the current information, and inappropriate release of information could jeopardize an investigation or even put officers and the public in danger. From the media participants, the duty officers learned that reporters are often calling only to confirm minimal information, because some agencies require reporters to have three confirmations of information before they can publish a story. Overall, this open discussion created a much better mutual understanding of the roles, mandates, challenges and goals. Before the meeting was closed, a round-table chance to speak for all parties ensured that every participant spoke about the experience of the meeting, and their impressions.

\section{Observations}

The police-media relationship can be understood largely as an approach-avoidance scenario, as most media representatives wanted change and about half of the duty officers were indifferent or wanted to avoid addressing the conflict. There was a motivation within the APS, however, to improve the working relationship between duty officers and the media, even though some officers were resistant or indifferent. Hence, the conflict resolution goal that emerged was to shift the duty officers from avoidance to agreement and willingness to enter an approach-approach relationship (Lewin's unfreezing stage) (1947). Increased willingness to change and collaborate, along with reduced structural challenges, it was speculated, should result in substantial improvements to the police-media working relationship. Improved situational factors (the times in which media are allowed to call) should alleviate intergroup tensions 


\section{(Cheldelin, Druckman, \& Fast, 2003).}

The results of both syndicate sessions and the larger group consensus were as expected. The main structural problem was the time in which the media were restricted to calling the duty office with inquiries. Surprisingly, none of the stakeholders present suggested expanding the time periods. I interpret this as a display of their willingness to be reasonable. After a lengthy discussion, the group determined that the times could be adjusted to better accommodate all of the different media time needs, as deadlines for completed stories vary between print, radio and televised agencies. For instance, updates to web-based stories are ongoing; television has specific deadlines before stories are aired; and the print media have different deadlines for their editors and printing processes.

The group identified new access times, which better meet the needs of the different news outlets, as well as the needs of the duty officers. Instead of 10:00 PM to midnight, the group decided on 8:30 to 9:30 PM, and then 10:30 to 11:30 PM would meet everyone's needs. These timeframes are more useful for a wider range of reporters, and also more effective for the duty officers, as the evening shift officers are still on duty between 8:30 PM and 9:30 PM and can better speak to what occurred during their shift, rather than passing information to the nightshift officer. A senior news editor commented after this exercise: "I can't believe that we actually came to consensus on these issues," referring mainly to existing competitive relationships between the media outlets.

The other main issue was a complaint by the duty officers that reporters regularly ask for sensitive information that cannot be provided. A related issue was the previously mentioned fishing or vague questions such as "anything to report?" The senior editors were receptive to these points, agreeing that fishing is not appropriate, but explained that the journalistic community is suffering the same demographic challenges as other industries, with mass baby boom retirements, and many younger reporters need more training and direction. The media representatives all expressed appreciation for the added insight into the role of the duty officers and advised that they would direct and educate their staff members on these issues. They also collectively asked that updates be provided on critical issues such as patient conditions. For example, when a release is issued stating that a person involved in a car accident was taken to the hospital in "critical condition," a change in this person's condition to "stable" affects the public's interest in the story; thus, reporters would appreciate such updates.

Both groups agreed that extending the work hours of PIO officers would potentially address all of the identified issues. Having a PIO on call during the day and evening shifts would alleviate many of these problems. However, this is not a perfect solution either, because there will still be major events and the need for inquires overnight, even if APS were to expand the PIO office hours. Considering APS is challenged for human resources, this solution is not likely to be implemented. Nevertheless, I agreed to take all of the suggestions back to the larger group of duty officers and APS Chief's executive office.

The media representatives were generally receptive to the workshop and expressed appreciation for APS taking the initiative to improve collaboration. Several of the participating duty officers reported afterward that they were initially apprehensive, but changed their minds after the workshop, feeling that it had derived positive outcomes, and more consensus than they expected. After the workshop took place, I addressed the entire duty office group, including the members who missed the meeting, advising them of the findings and recommendations that had emerged. They were generally receptive to the time changes and the possibility of expanding the PIO office. They were less receptive to sending updates on patient conditions and the status of events, as this would require more effort. When this topic was discussed the conversation turned to the content in our messages. Some officers were resistant to change, and argued to reduce the amount of information provided to the media, restricting it to only public safety related information- such as hazards, requests for assistance and road closures. It is interesting to note that these concerns came mainly from officers who were unable to attend the workshop. Those officers also complained that they were not included in the meeting. I assured them that the next meeting, if done, would be scheduled on a day when those officers could attend, and perhaps the ones who had attended the first meeting might need to be excluded due to their duties. At a meeting with APS executives in the Chief's office, I summarized the meeting and its findings. The executive stressed the need for transparency and availability to the media, and I was directed to rewrite policy for the duty officers, 
adjusting the availability times as discussed, and also clarifying the content of messaging to ensure consistency from the different duty officers in making media releases and answering media inquiries.

\section{Discussion and Conclusion}

This analysis and exercise are cursory, and only indicate the opportunity for a larger formal study. However, within its limited scope, the exercise confirmed that collaborative problem solving could improve cooperation between interdependent conflicted parties. The overall benefits of collaboration are clear; the process of working together improved communication and the relationship between the two groups. It reduced territoriality and gave people a sense of ownership in shared solutions. The structural issues were easily identified. The access hours were a relatively simple fix and were implemented.

Logistical challenges can hamper effectiveness of change. In this case, it was impossible to get all of the active duty officers into a meeting at the same time. It would be difficult to run separate meetings in order to include all of the duty officers, as the media stakeholders also find it challenging to attend long meetings. In the future, it would be most effective to have the officers on duty replaced, so that the entire duty office unit can attend the meeting. This may ensure better collaboration and buy-in as-well-as consistency between officers. Only six media representatives attended, and that number could have been twenty or more. Clearly, more focus must be placed on inclusion of all of the stakeholders; constant turnover and reassignment within APS, and in the media agencies creates a situation wherein continued consensus is impossible without periodic maintenance. Fragmentation and competition within the media community also frustrates finding lasting solutions that meet everyone's needs.

In future similar scenarios, more focus should be placed on how shared solutions are put into practice. Any alteration in policy requires careful attention to how those changes can be implemented and how they will affect the people involved. In this case, a successful reconciliation occurred; however, not all of the stakeholders were involved in the process. Feedback afterwards revealed that some people that were not involved had less buy-in for the proposed solutions. This is a clear example of the "reentry factor" described by Sampson (2003). In this case several duty officers went off for a meeting with media representatives and then returned with ideas for change. Non-participants did not experience the transformative aspect of the workshop and, therefore (it is speculated), had less buy-in for the agreed upon solutions. It is unknown if this occurred among the participating media representatives in this case.

This is another area that warrants future research.

These findings also corroborate Lewin's change management model (1947). The need for change could have been developed better among all participants, perhaps during initial interviews. Then, acceptance and internalization of proposed solutions (refreezing) could have been done more effectively through follow-up seminars, perhaps in the form of joint training (Cameron, \& Green 2004; Lewin, 1947). In this case, I could have spent more time gaining support from other Duty Officers to seek changes. Perhaps the same could have been encouraged among counterparts in the media industry. This also is an area for potential future research.

A future repeat of this exercise could include conflict resolution being integrated within a framework such as Lewin's model (Lewin, 1947), to ensure that the emerging collaborative solutions are implemented effectively and that the relationships are maintained. In this case, unfreezing can involve an increased focus, as early as the initial contact or in the preliminary interviews, on gaining buy-in from the stakeholders to work together for win-win solutions and to implement change. My initial invitation set the tone by including language indicating that collaboration is the goal. However, in the future, the outcome of similar exercises may be improved by personal phone calls or face-to-face conversations with the people invited, to provide a deeper explanation of our goals and create a greater impetus for change.

Having received positive feedback from the stakeholders after this first workshop, a certain degree of unfreezing can be expected to occur naturally, as word-of-mouth travels among local media professionals and APS duty officers. In particular, the media will likely be more willing to come out in larger numbers for the next meeting after they see that the police actually listened and implemented the changes that were agreed upon. Another positive outcome of this research is the exposure that duty 
officers and senior media professionals experienced regarding conflict resolution practices. The duty officers who participated in this exercise all spoke highly of its effectiveness, and are now more likely to seek collaboration within their future commands, and also with partner agencies in the community. This exercise indicates potential value in increased conflict resolution training for police officers. Similarly, media representatives expressed the same positive experience.

Future research should focus on a deeper analysis of the personal characteristics of participants, and structural aspects- in this case the system of communications between the duty officers and reporters. This research applies to scenarios wherein interdependent organizations with strong cultural identities must work effectively together. Military, prison guards, scholars, medical professionals, social workers, teachers, and administrators may all fit these criteria and may be suitable subject groups for future similar research.

Druckman's situational model (Cheldelin, Druckman, \& Fast, 2003) describes the significance of assessing the personal characteristics of involved parties as well as situational aspects that can cause tension. This model facilitates insights into the police-media relationship, but more could be done in analyzing the nuances of these complex organizational cultures and how they interact with others. This aspect needs careful attention in future research on interdependent organizations. Perhaps the most significant finding of this research was the complexity of even the most straightforward of conflicts. Dr. Byrne (2010) has described the complexity of conflicts using a metaphor of a social cube, which creates an image of the many interconnected dimensions that play a part in conflicts.

Overall, this exercise shed light on key issues, helped identify potential solutions, and engaged the partners to collaborate on win-win solutions that ultimately improved their collective public service; but there is room for much more improvement and a need for continuous attention to it. By improving communication and understanding each other's perspectives, participants found common ground and achieved their objectives. While the implementation of solutions was problematic, the research identified the significance of change management as an integral part of problem solving in the workplace. It has set a course for improved future happiness, if not true love, in the arranged marriage between interdependent groups such as police and the media.

About the Author: Robert Chrismas is a career police officer with twenty-eight years of Canadian law enforcement experience. He completed Bachelors programs in psychology, developmental studies and justice and law enforcement in 1988 and his Master of Public Administration degree (MPA) in 2008, at the University of Winnipeg and University of Manitoba. Robert is currently a Doctoral student of Peace and Conflict Studies at the Mauro Centre for Peace and Justice, University of Manitoba. Email: bchrismas@winnipeg.ca.

\section{References}

Becker, H. (1967). Whose side are we on? Social Problems, 14, 239-247.

Bellew, S., Tori, C., \& Liederbach, J. (2004). Police-media relations at critical incidents: interviews from Oklahoma City. Texas: University of North Texas.

Bonner, M.D. (2009). Media as social accountability: The case of police violence in Argentina. International Journal of the Press, 14, 296-312.

Boyle, R. (1999). Spotlight Strathclyde: police and media strategies. Corporate Communications: An International Journal, 4, 2, 93-97.

Bridges, W. (2003). Managing Transitions: Making the Most of Change, Second edition. Cambridge, MA, USA: Perseus Publishing.

Byrne, S. (2010). Personal communication, October $6^{\text {th }}$.

Byrne, Sean, Sandole, D., Sandole-Staroste, I., \& Senehi, J. (2009). Handbook in Conflict Analysis and Resolution. Oxford, UK: Routledge. 
Cameron, E., \& Green, M. (2004). Making Sense of Change Management: A Complete Guide to the Models, Tools and Techniques of Organizational Change. Virginia, USA: Sterling, Kogan Page Limited.

Cheldelin, S., Druckman, D., \& Fast, L. (2003). Conflict: From Analysis to Intervention. New York: Continuum.

Cooke, L., \& Sturges, P. (2009). Police and media relations in an era of freedom of information. Policing \& Society, 19, 4.

Crank, J. (1997,1998). Understanding Police Culture. Cincinnati, OH: Anderson.

Deuze, M. (2005). What is journalism? Professional identity and ideology of journalists reconsidered. Journalism, 6, 442-464.

Gladwell, M. (2002). The Tipping Point. New York: Back Day.

Graber, D.A. (1980). Crime, news and the public. New York: Praeger.

Guffey, J. (1992). The Police And The Media: Proposals For Managing Conflict Productively. American Journal of Police, X1, 1.

Hanitzsch, T. (2005). Journalists in Indonesia: Educated but timid watchdogs. Journalism Studies, 6, 493-508.

Herscovitz, H. G. (2004). Brazilian journalists' perceptions of media roles, ethics, and foreign influences on Brazilian journalism. Journalism Studies, 5, 1, 71-86.

Jeong, H. W. (1995). Peace and Conflict Studies: An Introduction. Burlington, VT: Ashgate.

Lewin, K. 1947. Frontiers in Group Dynamics. Human Relations, 15-41.

McCombs, M.E., Shaw, D.L. (1972). The agenda-setting function of mass media. Public Opinion Quarterly, 40, 176-187.

Nickels, E., \& Arvind V. (2008). Dimensions of police culture: a study in Canada, India, and Japan. Policing: An International Journal of Police Strategies and Management, 31, 2, 186209.

Niederhoffer, A. (1967). Behind the Shield: The Police in Urban Society. New York, NY: Doubleday.

Paoline, E. A., Myers, S., \& Worden, R. E. (2000). Police culture, individualism, and community policing: evidence from two police departments. Justice Quarterly, 17, 3, 575-605.

Prenzler, T. (1997). Is there a police culture? Australian Journal of Public Administration, 56, 4, 47-56.

Ramaprasad, J. (2001). A profile of journalists in post-independence Tanzania. Gazette, 63, $539-556$.

Sampson, C., Abu-Niner, M., Liebler, C., \& Whitney, D. (2003). Positive Approaches to Peacebuilding: A Resource for Innovators. Ohio, USA: Taos Institute Publications.

Sandole D. (2009) p. 49 in Cheldelin, S., Druckman D. \& Fast, L. (2003). Conflict: From Analysis to Intervention. New York: Continuum.

Schellenberg, J. A. (1996). Conflict Resolution, Theory, Research, and Practice. New York, USA: University of New York Press.

Selke, W., \& Bartoszek, M. (1984). Police and Media Relations: The Seeds of Conflict. Criminal Justice Review, 9, 25.

Sheufele, D.A. (1999). Framing as a theory of media effects. Journal of Communication, 49, 103-122.

Simmel, G. (1955). in Schellenberg, J. (1996). Conflict Resolution, Theory, Research, and Practice. State University of New York Press, Albany, New York.

Skolnick, J. H. (1994). Justice without Trial: Law Enforcement in Democratic Society, 3rd ed. New York NY: MacMillan.

Simmons, H. (1999). Media, police, and public information: from confrontation to conciliation. Communications and the Law, 21.2, June, 69, 1.

Splichal, S., \& Sparks C. (1994). Journalists for the 21st century. Tendencies of professionalization among first-year students in 22 countries. Norwood, NJ: Ablex.

Surrette, R. (1989). Media trials. Journal of Criminal Justice, 17, 293-308. 
Van Maanen, J. (1978). The asshole. in Manning, P.K. and van Maanen, John. (Eds), Policing: A View From the Street Santa Monica, CA: Goodyear Publishing, p. 221-38.

Van Maanen, J. (1974). Working the street: a developmental view of police behavior. in Jacob, H. (Ed.), The Potential for Reform of Criminal Justice. Beverly Hills CA: Sage p. 83- 130.

Weaver, D. H. (1998). The global journalist: News people around the world. Cresskill, NJ: Hampton.

Weaver, D. H., Randall, A. B., Brownlee, B. J., Voakes, P., \& Wilhoit G. C. (2007). The American journalist in the 21st century: U.S. news people at the dawn of a new millennium. Mahwah, NJ: Lawrence Erlbaum.

Westley, W. (1970). Violence and the Police: A Sociological Study of Law, Custom, and Morality. Cambridge, MA: MIT Press.

Zwell, M. (2000). Creating a Culture of Competence. USA: John Wiley \& Sons, Inc. 